\title{
Confusion between Two Amphotericin B Formulations Leading to a Paediatric Rehospitalisation
}

\author{
Mapi Fleury ${ }^{1,4} \cdot$ Caroline Fonzo-Christe $^{2} \cdot$ Charline Normand $^{3} \cdot$ Pascal Bonnabry $^{1,2}$
}

Published online: 30 April 2016

(c) The Author(s) 2016. This article is published with open access at Springerlink.com

\begin{abstract}
A heavily immunosuppressed, 43-kg, 9-year-old patient was recovering from a bone marrow transplant. Primary prophylaxis against invasive fungal infections was liposomal amphotericin B (AmBisome ${ }^{\circledR}, 2.3 \mathrm{mg} / \mathrm{kg}[100$ $\mathrm{mg}$ ] two times per week). Once home, following a first amphotericin $\mathrm{B}$ infusion, he presented with strong diarrhoea and vomiting; this was repeated after the second infusion. The clinical situation worsened rapidly and the patient was rehospitalised. On admission, he presented with acute renal failure. During the 2-week hospitalisation, renal function recovered progressively. A few days after returning home, a new administration of amphotericin B was again followed by diarrhoea and vomiting, together with shivering and fever. The child was again rapidly rehospitalised. Investigation revealed that the community pharmacist, relying on drug software, had selected an inappropriate substitute drug: the patient had been administered amphotericin B deoxycholate (Fungizone ${ }^{\circledR}$ ) and not liposomal amphotericin B. Depending on the indication, intravenous AmBisome ${ }^{\circledR}$ is usually administered at a dose between 3 and $5 \mathrm{mg} / \mathrm{kg}$ bodyweight; this dose can be increased to up to $10 \mathrm{mg} / \mathrm{kg} / \mathrm{day}$. Intravenous Fungizone ${ }^{\circledR}$, however, should be administered using an initial dose of
\end{abstract}

Mapi Fleury

mapi.fleury@chuv.ch

1 School of Pharmaceutical Sciences, University of Geneva, Geneva, Switzerland

2 Pharmacy, University Hospitals of Geneva, Geneva, Switzerland

3 Haemato-Oncology Unit, General Paediatrics Department, University Hospitals of Geneva, Geneva, Switzerland

4 Service de pharmacie, Rue du Bugnon 46, 1011 Lausanne, Switzerland
$0.25 \mathrm{mg} / \mathrm{kg}$ bodyweight, up to a recommended $1-\mathrm{mg} /$ $\mathrm{kg} /$ day dose. The child had thus received $100 \mathrm{mg}$ of Fungizone $^{\circledR}$, or ten times the recommended dose.

\section{Key Points}

Galenical forms of amphotericin B are not equivalents. With specific regard to amphotericin B deoxycholate (Fungizone ${ }^{\circledR}$ ), it must be remembered that the benchmark dose is $1 \mathrm{mg} / \mathrm{kg} /$ day.

The use of information technologies should in no way exempt healthcare professionals from a duty to critically monitor prescriptions and carry out safety checks.

\section{Introduction}

Adverse drug events (ADEs) are an unfortunate but recurrent problem in healthcare systems. In paediatric patients, medication-related incidents accounted for $0.5-3.3 \%$ of emergency visits and $0.16-4.3 \%$ of hospital admissions; $20.3-66.7 \%$ of these were estimated to be preventable [1]. Beyond the everyday problems of mistaking the names of closely related drugs (i.e. look alikes or sound alikes), different galenical formulations of the same active ingredient, which are not equivalents from a prescriptive point of view, present an added risk of confusion.

The present article describes the case of a paediatric patient who experienced a serious ADE because of a mix- 
up between two forms of intravenously administered amphotericin B: a conventional deoxycholate formulation (Fungizone ${ }^{\circledR}$ ) and the liposomal formulation (AmBisome $\left.{ }^{\circledR}\right)$. Subsequently, our discussion is in three parts. Part one concentrates on the different available formulations of amphotericin B and their associated nephrotoxicity. To provide the context surrounding the factors contributing to this error, part two briefly explains how this drug is dispensed in Switzerland. Using an Ishikawa diagram (a rootcause analysis), part three synthesises the conclusions reached on the causes of this ADE and suggests means of avoiding any repetition of this dangerous mistake.

\section{Case Report}

A heavily immunosuppressed 9-year-old boy weighing 43 $\mathrm{kg}$ was recovering from a bone marrow transplant. Immunosuppressive therapy consisted of prednisolone 0.8 $\mathrm{mg} / \mathrm{kg} /$ day, mycophenolate mofetil $20 \mathrm{mg} / \mathrm{kg} /$ day split into two equal doses and two sessions of photopheresis every 2 weeks. Primary prophylaxis against invasive fungal infections was a prescription of liposomal amphotericin B (AmBisome ${ }^{\circledR}, 2.3 \mathrm{mg} / \mathrm{kg}$ (100 mg) two times per week). Once at home, following a first infusion of amphotericin B, the patient presented with strong diarrhoea and vomiting, and this was repeated after the second infusion. The clinical situation worsened rapidly and the patient was rehospitalised the same day. On admission, he presented with acute renal failure. Over the following 2 weeks of hospitalisation, renal function recovered progressively; the decompensation was attributed to the additional adverse effects of the nephrotoxic treatments prescribed in the context of the earlier transplant. These drugs were consequently adapted or stopped; however, this implied a greatly increased risk of the development of a graft-vs.-host disease. Levels of corticosteroids were increased, leading to difficulties in managing arterial blood pressure and the recurrence of insulin-dependent diabetes mellitus. During hospitalisation, amphotericin B was recommenced, and three infusions were administered with no notable problems.

A few days after returning home, a new administration of amphotericin B was again followed by diarrhoea and vomiting, together with shivering and fever. The child was once again rapidly rehospitalised, and given a combination antibiotic on the suspicion of an infected central venous catheter.

Suspecting a medication error, the clinical team asked the patient's family to bring in the infusion bags used in their home. By examining the labels on the bags, it was discovered that the drug administered had in fact been amphotericin B deoxycholate (Fungizone ${ }^{\circledR}$ ) and not liposomal amphotericin B (AmBisome ${ }^{\circledR}$ ). This had led to the patient experiencing an amphotericin B overdose. He eventually recovered from this after several extra weeks in hospital.

Depending on the indication, intravenous AmBisome ${ }^{\circledR}$ is usually administered at a dose between 3 and $5 \mathrm{mg} / \mathrm{kg}$ bodyweight; this dose can be increased to up to $10 \mathrm{mg} /$ $\mathrm{kg} /$ day. Intravenous Fungizone $^{\circledR}$, however, should be administered using an initial dose of $0.25 \mathrm{mg} / \mathrm{kg}$ bodyweight, up to a recommended $1-\mathrm{mg} / \mathrm{kg} /$ day dose. The child had thus received $100 \mathrm{mg}$ of Fungizone ${ }^{\circledR}$, or ten times the recommended dose. The community pharmacy that dispensed the drugs was contacted and questioned. When AmBisome $^{\circledR}$ is not in stock, pharmacy staff choose an alternative from amongst the propositions given by the pharmacy's software; this sorts available drugs by principal active ingredient, the recommended International Nonproprietary Name (INN). AmBisome ${ }^{\circledR}$ had thus been substituted by Fungizone ${ }^{\circledR}$ on the assumption that they were generic drug formulations. Pharmacy dispensary records showed that the patient had been given Fungizone ${ }^{\circledR}$ instead of AmBisome ${ }^{\circledR}$ each time he had come for his out-patient prescription.

\section{Discussion}

\section{The Nephrotoxicity of Different Formulations of Amphotericin B}

Amphotericin B plays a central role in the prevention and treatment of severe, deep systemic fungal infections. The conventional formulation is amphotericin B deoxycholate (Fungizone ${ }^{\circledR}$ ). Nevertheless, this formulation frequently causes renal function disorders, including a decreased glomerular filtration rate. Indeed, the two studies involving the largest cohorts to associate amphotericin B deoxycholate with nephrotoxicity reported an incidence of over $25 \%$ in the 494 and 643 patients treated with the drug [2, 3]. One suggested mechanism [4] for this ADE is a combination of two phenomena. The first phenomenon involves amphotericin B directly inducing renal vasoconconstriction or provoking glomerular feedback owing to its antifungal influence on sodium entering juxtaglomerular cells. The second phenomenon is the result of tubular toxicity, which alters ions permeability. The binding of amphotericin B to the cholesterol in cell membranes probably mediates this permeability in part. However, it is probably also partly mediated by the deoxycholate detergent, which solubilises the original drug formulation, but not the liposomal one. To avoid the toxicity induced by this excipient, other formulations were developed, and they did indeed cause fewer ADEs of this type [5]. Three other galenical formulations 
are currently available on the global market. These include a lipid complex formulation of amphotericin B phospholipids $\left(\right.$ Abelcet $\left.^{\circledR}\right)$, a liposomal formulation of amphotericin B liposomes (AmBisome ${ }^{\circledR}$ ) and a lipid formulation containing a complex of amphotericin $\mathrm{B}$ and sodium cholesteryl sulphate $\left(\right.$ Amphotec $\left.^{\circledR}\right)$. The case study described here took place in Switzerland, where only Fungizone ${ }^{\circledR}$ and AmBisome ${ }^{\circledR}$ are currently available on the market. To put the contributing factors of this error into context, the second part of our discussion briefly describes how drugs such as amphotericin B are dispensed on a patient's discharge from hospital in Switzerland.

\section{Dispensing Drugs at Patient Discharge from Hospital}

In Switzerland, there is no list of restricted drugs that can only be dispensed by hospital pharmacies. Furthermore, for regulatory reasons, when a patient is discharged, hospital pharmacies are not allowed to dispense their drugs for outpatient treatment. The hospital physician writes a prescription listing the necessary drugs, but the patient or his/ her family must go to outpatient institutions, such as community pharmacies, for the drugs to be dispensed. Regulations demand that the pharmacist must personally validate each prescription. Furthermore, the pharmacist must follow the minimum criteria required by the explicit procedures for monitoring doses and prescription restrictions, and if he/she were to detect any major contraindications, then he/she should contact the prescribing physician [6].

\section{An Analysis of the Error and Suggested Prevention Strategies}

In her thesis, Kaestli [7] evaluated the risks of the discontinuity of pharmaceutical care at paediatric hospital discharge. A systematic prospective analysis of the risks involved in this process was made using the FEMCA method (Failure modes, effects, and criticality analysis). This work synthesised the factors contributing to ADEs at paediatric hospital discharge into a root cause (or Ishikawa) diagram, and it gave particular attention to the role of community pharmacists. Figure 1 is a modified version of that diagram; it focuses closely on the most important error that took place in the case at hand, the dosage error.

Kaestli's potential errors contributing to ADEs are shown in black. On examining our patient's case, we have highlighted (in blue) three factors that seem to have been particularly linked to the error at hand: an unusual pathology/treatment; an unfamiliarity with hospital treatments; and perhaps, because to err is human, forgetfulness/carelessness. We discuss below the measures that have since been put in place to avoid these problems.

Nevertheless, these factors failed to explain the problem in its entirety, and it seemed necessary to add a series of further potential risks or problems (in red) that might also have contributed to the error. In the diagram, the 'Wrong dosage' branch now features three supplementary potential causes of an error: (1) the absence of a shared patient medical record; (2) inadequate software, or reliance on software alone; and (3) insufficient safety checks. These sub-branches are evaluated below.

The primary factor contributing to the error was the absence of a shared medical record. The healthcare professionals dealing with the patient do not all have access to the same information, notably, in the present case, with regard to the chosen therapy. Had information on the preparation dispensed by the community pharmacist been available immediately to hospital physicians, successive administrations of the wrong drug may have been avoided.

One potential future solution to this problem will undoubtedly come in the form of health information technologies (HIT); a shared electronic medical record available to all the healthcare professionals involved in patient management is, for example, slowly being introduced across Switzerland [8], but it is not yet the norm. Until such exchanges of information are the norm, healthcare professionals should make the most of every opportunity to communicate with each other. If the prescription is the only interaction between the hospital physician and the community pharmacist, adding a reference stating that a prescribed drug "must not substituted" could easily be done. Involving patients and their families and training them to be active expert participants in their own treatment, as suggested by the Institute for Safe Medication Practices (ISMP) [9], would be another way of helping to improve safety and the continuity of care.

Although HIT might have improved the situation in the present case in terms of continuity of patient safety, information technology was also the second contributing factor to this medical error. A branch concerning the potential dangers of HIT was thus added to the Ishikawa diagram. Perhaps because validation of the information contained in HIT and the way in which they treat data and algorithms are not subject to any strict regulatory regime, there is a perceived lack of critical judgement in the face of new technologies, despite healthcare professionals knowing these systems are not infallible. In the same way, when data are badly presented, poor interfaces do not help users work to the best of their abilities. In the case presented here, we can suppose that the presentation of the data is one of the contributing factors to the final error. Working with the INN, the software proposes pharmaceutical formulations that seem to be bioequivalents. 


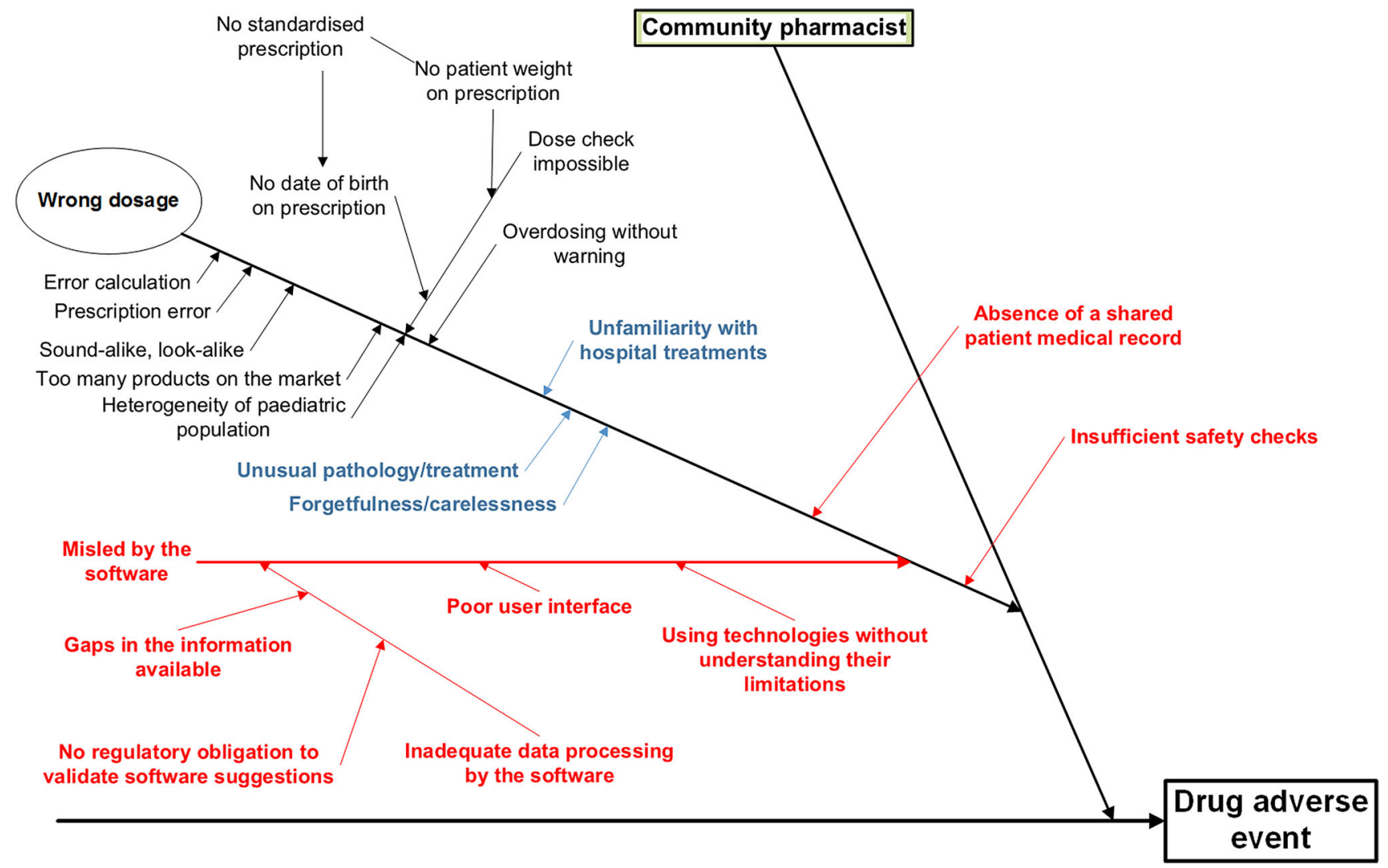

Fig. 1 Adapted version of Kaestli's Ishikawa diagram focusing on the factors that contributed to a dosage error by a community pharmacist. Blue factors were particularly relevant in this adverse

Thus, we cannot deal with the causes of this error without involving amphotericin B's INN. To ensure unambiguous prescription, using the INN system is generally recommended, and attributing INNs is one of the World Health Organization's roles in standardisation. The specialist team examining a particular substance aims to precisely identify its composition and find close links to other substances used as drugs. When a new INN is proposed, the team tries to ensure that there are no conflicts or confusions with existing names, no undesirable medical connotations and no other particular linguistic problems [10]. This system no longer appears to be sufficient. Today's galenical technologies both complicate and change drugs' pharmacokinetics and pharmacodynamics and thus how they should be dosed. The attribution of new INNs should, therefore, take into consideration the fact that many principal ingredients are no longer interchangeable. There are already examples of this, although they are rare: paclitaxel poliglumex is a biodegradable polymer of paclitaxel; its INN distinguishes it from conventional paclitaxel. This important change in thinking should begin today as INNs are the foundation of the Anatomical Therapeutic Chemical classification system and defined drug event. The contributing factors in red are newly identified ones and were added to the diagram subsequent to this case study Reproduced from Kaestli et al. [7], with permission

daily dose measuring. Anatomical Therapeutic Chemical codes are widely used in drug databases, forming part of the structured data that flow through prescription systems or automated dispensing cabinets.

In the case of amphotericin $\mathrm{B}$, one solution might be to attribute the drug an INN (Modified) [INNM]. This possibility already exists, especially in cases where the active molecules need to be expanded for various reasons, such as formulation purposes. Indeed, with this in mind, we have now asked the World Health Organization to give amphotericin B deoxycholate an INNM and add it to the classification.

While awaiting this addition, and wherever possible, whenever software makes a therapeutic suggestion it is important that all entries be validated by a pharmacist.

The final contributing factor to this medical error, and the last branch added to the Ishikawa diagram, concerns the critical monitoring that should be carried out for medical prescriptions. We wish to note that purely inpatient hospital experiences did not help us to better address the specific problem of confusion in the formulations of amphotericin B. During informal free discussions about this error with teams of healthcare professionals, we realised that certain 
colleagues were also unaware of the differences between products. We learnt that similar incidents had occurred within our institution, and we learnt of other identical errors that had happened in other local hospitals. Faced with the possibility of a repeat incident, we decided that immediate action was necessary for the safety of our patients. Because we were not in a position to influence high staff turnover rates, rapid staff training for those involved or any other type of long-term solution, we managed to block the prescription of conventional amphotericin B using our hospital's paediatric department Computerized Provider Order Entry system, and remove Fungizone $^{\circledR}$ from the drug stocks in our care units.

This digression on our local experience highlights the final branch added to Fig. 1: whatever the situation, critical monitoring of prescriptions is a must. This also brings us to the first three (blue) branches on the diagram that we believed were significant contributing factors in the error: unusual pathology/treatment, unfamiliarity with hospital treatments, and forgetfulness/carelessness. We believe that adequate safety measures should have flagged or stopped these issues.

Indeed, despite galenical changes, amphotericin B remains a drug with a narrow therapeutic window, and it must be handled with great care. It remains to be seen precisely what 'great care' implies in terms of potential solutions. In 2007, the ISMP published advice on avoiding confusion between amphotericin B drugs, as these had caused previous fatal accidents [9]. In the same year, the National Patient Safety Agency published a Rapid Response Report on the same theme [11]; the Francophone journal, Prescrire, followed up on this in 2009 [12].
The advice in Table 1 is a synthesis of the recommendations in Prescrire, from the UK's National Health Service and from the ISMP [10-12], as well as from the Ishikawa diagram in Fig. 1.

\section{Conclusion}

Different formulations of amphotericin B are not interchangeable. A confusion between the deoxycholate and liposomal formulation caused a series of serious ADEs for a young child, although the final outcome was favourable. In the case reported, a community pharmacist made an inappropriate drug substitution that caused the ADEs. In our discussion, we explained the differences between amphotericin B formulations, notably the specific toxicity associated with the deoxycholate detergent in Fungizone ${ }^{\circledR}$. Subsequently, we put this error into the Swiss context, which explained how a drug designed for specific intensive care can be dispensed by a community pharmacy. Developing on an Ishikawa diagram taken from the literature, we brought together all the potential contributing factors to this error and added those that were identified specifically following analysis of the ADE. Thus, the absence of a shared medical record, the use of health information technologies without a solid understanding of their intrinsic limitations, and the insufficient application of safety checks when confronted with unfamiliar pathologies were all major contributing causes to this error.

We proposed some solutions to help avoid these contributing factors, notably using medical prescriptions to better transmit important information, information that a

Table 1 Synthesis of recommendations for limiting adverse drug events

Detailed information on drugs must be available immediately and easily

Train and inform staff about any non-equivalent formulations sharing the same International Non-proprietary Name, and plan for labelling them differently or flagging them in some other way

Doubt never benefits the patient. Before prescribing, dispensing or administering a drug that raises doubt or is unfamiliar, the drug name and dose must be verified

Include 'technological' formulations of drugs on your establishment's high-alert list of medications to watch out for, and perform a careful validation of drug entries when putting in place computerised prescription or dispensing systems

For drugs on the high-alert list, use the complete generic name including excipients, formulation specificities and the brand name at each stage in its use, from prescription to administration, i.e. amphotericin B deoxycholate (Fungizone ${ }^{\circledR}$ ) or amphotericin B liposomal (AmBisome ${ }^{\circledR}$ )

When a product is designated as 'high risk', explaining the risks associated with that drug makes the message sink home

Prescribe the drug as a dose/kg/day and as a total daily dose

Computer software does not mean that critical monitoring of drug prescriptions no longer needs to be carried out, and pharmacological knowledge is mandatory

With specific regard to amphotericin B deoxycholate (Fungizone ${ }^{\circledR}$ ), remember the benchmark dose of $1 \mathrm{mg} / \mathrm{kg} / \mathrm{day}$

When amphotericin B must be handled or dispensed outside of a specialised pharmacy, its storage must be subject to an appropriate risk evaluation

Ensure that patients (and their families) take an active part in their treatment safety by teaching them about the drugs that are administered to them 
suitably informed patient can substantiate if he/she has expert understanding about his own treatment. A table synthesising recommendations for limiting ADEs was also presented. Finally, because everyone is responsible for a link in the patient-safety chain, we brought up the possibility of healthcare professionals, not national agencies, suggesting modifications to the INN classification to the World Health Organization. This is precisely what we have done in proposing that amphotericin B deoxycholate be classified as an INNM.

\section{Compliance with Ethical Standards}

This child's parents understood the necessity of publishing news of this incident in the form of a case report and have signed an informed written consent form to this effect.

Conflict of interest Mapi Fleury, Caroline Fonzo-Christe, Charline Normand and Pascal Bonnabry declare that they have no conflict of interest.

Funding No financial support was received for the preparation of this manuscript.

Open Access This article is distributed under the terms of the Creative Commons Attribution-NonCommercial 4.0 International License (http://creativecommons.org/licenses/by-nc/4.0/), which permits any noncommercial use, distribution, and reproduction in any medium, provided you give appropriate credit to the original author(s) and the source, provide a link to the Creative Commons license, and indicate if changes were made.

\section{References}

1. Zed PJ, Black KJ, Fitzpatrick EA, Ackroyd-Stolarz S, Murphy NG, Curran JA, et al. Medication-related emergency department visits in pediatrics: a prospective observational study. Pediatrics. 2013;163:477-83.
2. Bates DW, Su L, Yu DT, Chertow GM, Seger DL, Gomes DR, Platt R. Correlates of acute renal failure in patients receiving parenteral amphotericin B. Kidney Int. 2001;60(4):1452.

3. Harbarth S, Pestotnik SL, Lloyd JF, Burke JP, Samore MH. The epidemiology of nephrotoxicity associated with conventional amphotericin B therapy. Am J Med. 2001;111(7):528.

4. Sterns RH, Emmett M, Forman JP. Amphotericin B nephrotoxicity. In: Post TW, editor, UpToDate. Waltham: UpToDate. [Accessed 25 Jan 2016].

5. Mistro S, Maciel Ide M, de Menezes RG, Maia ZP, Schooley RT, Badaró R. Does lipid emulsion reduce amphotericin B nephrotoxicity? A systematic review and meta-analysis. Clin Infect Dis. 2012;54(12): 1774.

6. Conseil d'Etat du Canton de Fribourg. Ordonnance sur les produits thérapeutiques. 2010. https://www.fr.ch/dsas/files/pdf4/f_ produits_th_rapeutiques_opth.pdf. Accessed 25 Jan 2016.

7. Kaestli L-Z. T. Amélioration de la continuité des soins pharmaceutiques aux patients pédiatriques sortant de l'hôpital. [dissertation on the internet]. [Geneva (Switzerland)]: University of Geneva; 2015. Available from: http://pharmacie.hug-ge.ch/sites/ pharmacie/files/rd/theses/Kaestli_Zoe_these.pdf. Accessed 21 Mar 2016.

8. Office fédéral de la santé publique. Loi fédérale sur le dossier électronique du patient (LDEP). 15.12.2015. http://www.bag. admin.ch/themen/gesundheitspolitik/10357/10360/index.html? lang=fr. Accessed 31 Jan 2016.

9. Institute for Safe Medication Practices (ISMP). Worth Repeating ... Preventing mix-ups between various formulations of amphotericin B. ISMP Medication Safety Alert! eds. September 6, 2007:1. https://www.ismp.org. Accessed 25 Jan 2016.

10. World Health Organisation WHO [homepage on the internet]. Guidelines on the Use of INNs for Pharmaceutical Substances. 1997. http://www.who.int/medicines/services/inn/innguidance/ en/. Accessed 25 Jan 2016.

11. National Patient Safety Agency. Rapid Response Report supporting information. 3.09.2007. http://www.nrls.npsa.nhs.uk/ EasySiteWeb/getresource.axd?AssetID=60262\&type=full\&service type=Attachment. Accessed 31 Jan 2016.

12. Prescrire Rédaction. Amphotéricine B injectable: gare aux confusions entre formes lipidiques et non lipidiques. La Revue Prescrire. 2009;29(311):672-4. 